\title{
Linking Plant Diversity and Dietary Diversity of Home Gardens: Examining the Nexus Through Structural Equation Modelling
}

\author{
W. M. D. K. Marasinghe, J. C. Edirisinghe" ${ }^{\#}$ and L. D. M. N. Lokuge \\ Department of Agribusiness Management, \\ Faculty of Agriculture and Plantation Management, \\ Wayamba University of Sri Lanka, Makandura, Gonawila (NWP). \\ ${ }^{\#}$ Corresponding Author: \\ E-mail: jagathed@yahoo.com
}

\begin{abstract}
Home gardens are the best solution to face global food crisis ahead. The diversified diet helps to reduce the micronutrient deficiency and the risk of chronic diseases. Purpose of this study is to identify the nexus between dietary diversity and plant diversity of the home gardens in Kandy district, Sri Lanka and to understand the determinants affecting the diversity of the home garden. One hundred and thirteen home gardens, belonging to six Divisional Secretariat divisions in Kandy district were randomly selected and data were collected by face to face interviews. Plant diversity was measured by Shannon Index (SI) and dietary diversity by an index prepared by using Food and Agriculture Organization's Dietary Diversity Index (DD20). Data were analysed through Structural Equation Modelling (SEM) method. Age of the garden owner, education level of the spouse, Health Perception Index (HPI), Constraints on Gardening Index (CGI) and Income Expectation Index (IEI) significantly affect the plant diversity of the home garden. According to the SEM results, there is a positive significant relationship between dietary diversity of the household and plant diversity of home gardens.
\end{abstract}

KEYWORDS: Dietary diversity, Home gardening, Plant diversity, Shannon Index, Structural Equation Modelling

\section{Introduction}

World hunger is becoming a more challenging issue, where developing nations have been mostly affected. Every one in nine people on earth, does not have enough food to lead a healthy active life and, hunger kills more people each year than AIDS, malaria and tuberculosis combined. Amidst these facts, developing nations rank at the top position, while being accountable for 98 percent of the world hunger population (FAO, 2015). 
According to the causes of this alarming problem, some proclaim that rapid population growth is the major root, while some argue that it is due to the poverty, instability and poor infrastructure. Despite the causes, world hunger and food security share a strong relationship, in a way which a failure of meeting the pillars of food security (availability, access, stability and utilization) opens the path to the problem of world hunger.

It is projected that, the global population will be 9.1 billion by 2050 , and the food production will have to be increased by 70 percent in order to feed everyone. Moreover, nations should launch measures to combat poverty and hunger, while adapting to climate changes, and using scarce natural resources more efficiently (FAO, 2009). However, another global challenge lies with the reduction of arable lands accompanied by the population growth and technological advancements through creating a vague situation for the means of feeding the growing population. In light of this, home gardening will have a greater impact as it is one of the most convenient ways of ensuring household food security. A well-developed home garden has the capability of fulfilling the daily dietary requirements of a family by supplying most of the non-staple foods such as roots and tubers, vegetables and fruits, legumes, spices and livestock products. Therefore, home gardening is increasingly becoming popular among households as it provides direct access to nutritionally rich foods, secures food provision during shortages, generates additional sources of income, and increases purchasing power (FAO, 2010). As a result of this, it will weaken the adverse impacts which will be arisen from reduction of arable lands and instabilities of economic aspects.

However, Sri Lanka is also now experiencing a nutritional transition due to urbanization, economic growth and changes in life style patterns. According to Jayawardena et al. (2014), Non-Communicable Diseases (NCDs) have turned out to be a severe burden during last two decades, while recording significant proportions for hypertension, obesity, dyslipidaemia, metabolic syndrome, diabetes and prediabetes. Furthermore, diet-related chronic diseases had been responsible for 18.3 percent of total mortality and 16.7 percent of hospital expenditure in Sri Lanka, while lack of dietary diversity is becoming the major cause. Nutritionists have identified dietary diversity as a key component of high quality diets (Ruel, 2006), where home gardening plays a crucial role in generating dietary diversity.

With reference to the Sri Lankan context, the area under home gardens has been reported as 14.3 percent (FAO, 2009), and reflected an annual growth of 1.6 percent from the total number (DCS, 2002). Together with this increasing trend, if all inhabitants are encouraged to practise home gardening, everyone will have access to a high quality diet regardless of financial and space constraints. In this context, this study aims to investigate the nexus between plant diversity and dietary diversity, while identifying the determinants affecting the diversity of a home garden. 


\section{Methodology}

\section{Study Area and Data Collection}

Home gardens in mid country are said to be high in diversity (Jacob and Alles, 1987). Therefore, the Kandy district, a major area in the mid country, was selected as our study area.

During February, 2015 to May, 2015, data were collected from 113 households who practise home gardening in 15 Grama Niladhari (GN) divisions under six Divisional Secretariat (DS) divisions (Kandy Four Gravels and Gangawata Korale, Kundasale, Udunuwara, Yatinuwara, Pathadumbara and Harispattuwa) in Kandy district.

Data on demography, food consumption, perceptions on home gardening and home gardening practices were obtained through face to face interviews with the support of a pre tested questionnaire. In addition, a plant count of useful crops in home garden was separately taken to calculate the biodiversity of the home garden.

\section{Conceptual Framework}

By employing five point Likert scaled questions, three indices which lie between 0 and 1, were constructed using the Equation 1. Specific scores were given to each question and total scores were calculated to each household as;

$$
\text { Index }=\frac{\text { Total score obtained by the household }}{\text { Maximun possible score }}
$$

The three indices are namely 'Health Perception Index (HPI)', 'Constraints on Gardening Index (CGI)', and 'Income Expectation Index (IEI)'. HPI expresses the attitude of the home garden owner on gardening, with respect to health (both physical and mental), food and nutrition security and safety. CGI shows the problems that the owner faced while maintaining the home garden. This index takes into account the availability of resources (land, labour and capital: credit, insurance, planting materials, fertilizer and pesticides), pest and disease problems, conceptual and marketing problems. IEI gives the level that the respondent's objective of earning money from his or her home garden.

Dietary Diversity 20 Index (DD20) gives the dietary diversity of the household as a ratio. Using the Equation 2, DD20 was calculated by getting data on 24 hours dietary recall. Twenty food groups were developed according to the dietary diversity measurements given by Kennedy et al. (2010). These groups are cereals, pulses, white roots and tubers, vitamin A rich vegetables, dark green vegetables, other vegetables, vitamin A rich fruits, other fruits, red meat, white meat, eggs, fish and sea food, nuts and seed, milk products, tea and coffee, soft drinks, spices, oils and fats, sweets and other foods. 
Shannon Index (SI) stated in the Equation 3, represents the proportional abundance or evenness, accounting for the land shares allocated to each crop, as well as the number of crops. It gives higher values when the relative abundance of the different species in the sample is even and low values when few species are more abundant than the others (Korale-Gedara et al., 2012).

Shannon Index $(S I)=-\sum_{\mathrm{i}=1}^{n} P_{\mathrm{i}} \ln P_{\mathrm{i}}$

Where, $P_{i}$ denotes the proportion of $\mathrm{i}^{\text {th }}$ species, while $\mathrm{n}$ denotes the number of species.

\section{Data Analysis}

Both descriptive and inferential statistics were used to analyse data. Analysis was carried out in Stata 13, and a Structural Equation Modelling (SEM) was utilized to identify the nexus between plant diversity and dietary diversity and also, to determine the drivers of plant diversity.

\section{Structural Equation Modelling (SEM)}

Structural Equation Modelling (SEM) is a series of statistical methods, which is expanding rapidly with its estimation techniques, modelling capacities, and breadth of applications (Lei and Wu, 2007). SEM allows researchers to test a conceptual or theoretical model through a combination of factor analysis and regression or path analysis (Hox and Bechger, 2000).

In this study, we incorporated SI and DD20 to the SEM as endogenous variables, while taking following as exogenous variables: age of the garden owner, gender of the household head, education level of the spouse, size and total income of the household, size of the home garden, HPI, CGI and IPI. Consequently, the nexus between Shannon diversity and dietary diversity of an $x^{\text {th }}$ household was examined through multiple regressions using the Equation 4 and 5, where $\varepsilon_{1}$ and $\varepsilon_{2}$ serve as latent variables, which make disturbances through set of unspecified causes of the SI and DD20, respectively.

$$
\begin{gathered}
S I_{x}=\beta_{0}+\beta_{1} \text { age }+\beta_{2} \text { gender }+\beta_{3} \text { edu.spouse }+\beta_{4} \text { household size }+ \\
\beta_{5} \text { income }+\beta_{6} \text { homegarden size }+\beta_{7} H P I+\beta_{8} C G I+\beta_{9} I P I+\varepsilon_{1} \\
D D 20_{x}=\gamma_{0}+\gamma_{1} S I+\varepsilon_{2}
\end{gathered}
$$


Where, $\beta$ s and $\gamma \mathrm{s}$ are the coefficients to be estimated.

\section{Results and Discussion}

\section{Descriptive Statistics of the Sample}

Our sample consists of 113 respondents with an average household size of 4, while recording a wide diversity for the age of the garden owner, with a mean of 53 years. With respect to the educational status, it seems that there is no significant gap between the level of education of the household head and the spouse, where 89.4 percent of the sample accounts for male household heads. Further, data highlight that, not all households engage in home gardening, utilize it as an income source. While reporting an average of Rs. 55,500/= for the total income, only 64 percent of the sample makes a contribution from home gardening for the total income. However, out of this 64 percent, export agricultural crops and fruit crops appear as most prominent crops which are popular among majority of households in generating income (Figure 1). Besides, it is interesting to note that, size of the home garden, number of plant species and number of plants are reflecting a wide array, implying a growing trend of home gardening regardless of the space limitations (Table 1).

Table 1. Descriptive statistics of the sample

\begin{tabular}{ccccc}
\hline Attribute & Mean & $\begin{array}{c}\text { Standard } \\
\text { Deviation }\end{array}$ & $\begin{array}{c}\text { Min. } \\
\text { value }\end{array}$ & $\begin{array}{c}\text { Max. } \\
\text { value }\end{array}$ \\
\hline Age of the owner & 52.5 & 11.1 & 22 & 83 \\
Household size & 4.0 & 1.3 & 1 & 8 \\
Education level of the household head & 12.1 & 2.2 & 0 & 19 \\
Education level of the spouse & 12.3 & 2.4 & 0 & 19 \\
Total income (Rs.) & 55505.6 & 31010.0 & 8750 & 180000 \\
Size of the home garden (perches) & 44.8 & 54.9 & 8 & 480 \\
Number of plant species & 36.0 & 16.3 & 6 & 85 \\
Number of plants & 270.7 & 390.7 & 12 & 3669 \\
\hline
\end{tabular}

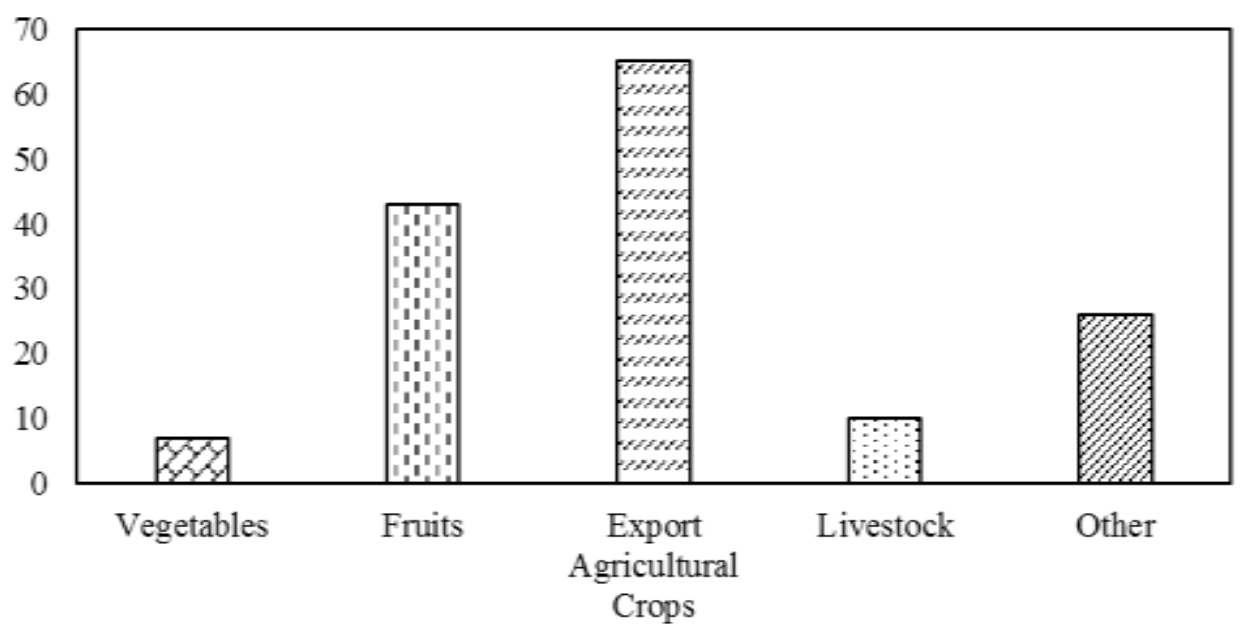




\section{Figure 1: Different varieties employed in home gardens in Kandy district SI and DD20 Indices}

As SI shows both richness and abundance of species in a particular community, it is a better indicator to express the plant diversity. The left-skewed distribution of the SI infers that, a greater proportion of our sample is rich in plant diversity (Figure 2). Conversely, the DD20 seems to be more or less like a symmetric distribution, highlighting that dietary diversity of the households in the sample is almost fairly laid between low and high indicators (Figure 3). This may be due to the diversity which exhibits in the household income because, purchasing power creates a strong link with the dietary diversity. Literature too suggests that there is a positive relationship between the dietary diversity and income (Theil and Finke, 1983; Pollack, 2001; Regmi, 2001; Ruel, 2003; Rashid et al., 2006) and thus, household income might play a vital role in this regard.

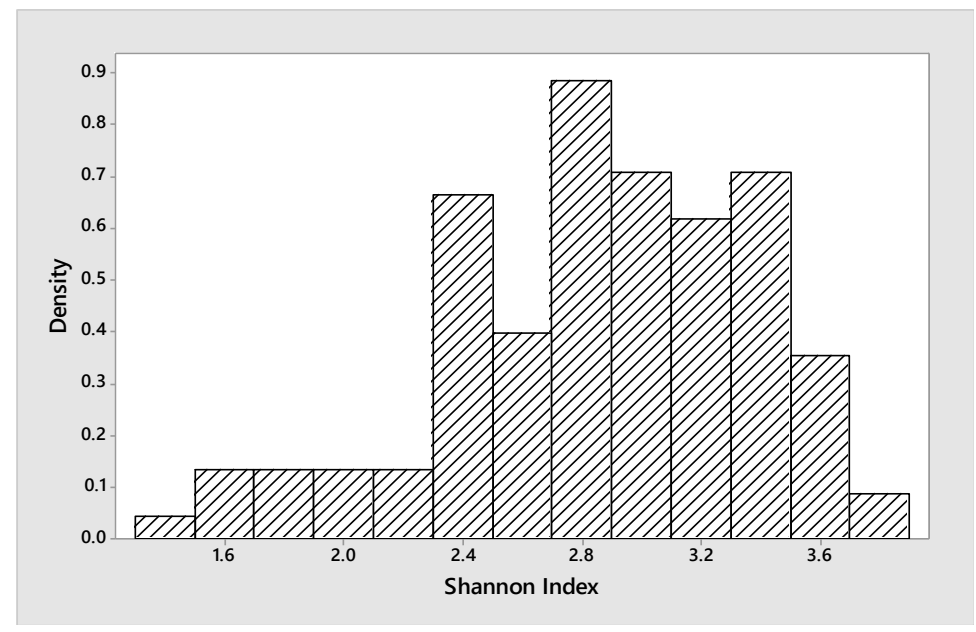

Figure 2: Distribution of the SI

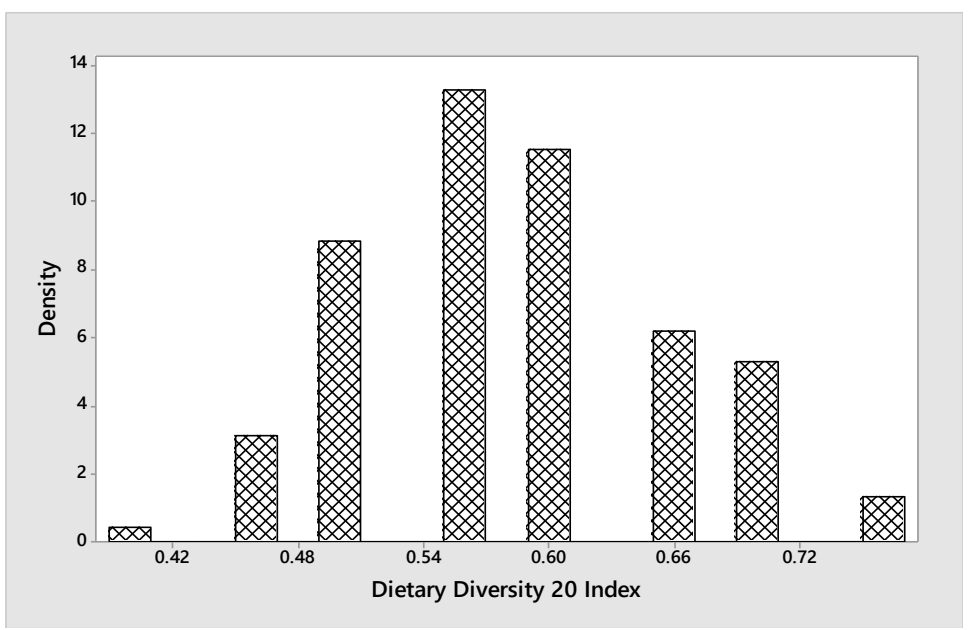




\section{Figure 3: Distribution of the DD20}

\section{SEM}

Conforming to the key assumption of having uncorrelated disturbances of effect variables with their specified causal variables, Chi-square test for the model was not significant denoting the fact that the model we employed for the analysis is adequate. Therefore, rest of the study is based on the interpretations which produced through the path diagram and the corresponding output of the SEM (Figure 4, Table $2)$.

Amidst the significant variables, age, education level of the spouse and HPI show a positive relationship with the SI, while with the CGI and IEI, a negative relationship is observed.

People gather knowledge through experience. They realize the usefulness of high biodiversity with the time. Therefore, they tend to grow a greater number of crop species. This may be the reason to have a positive and significant coefficient for age of the owner.

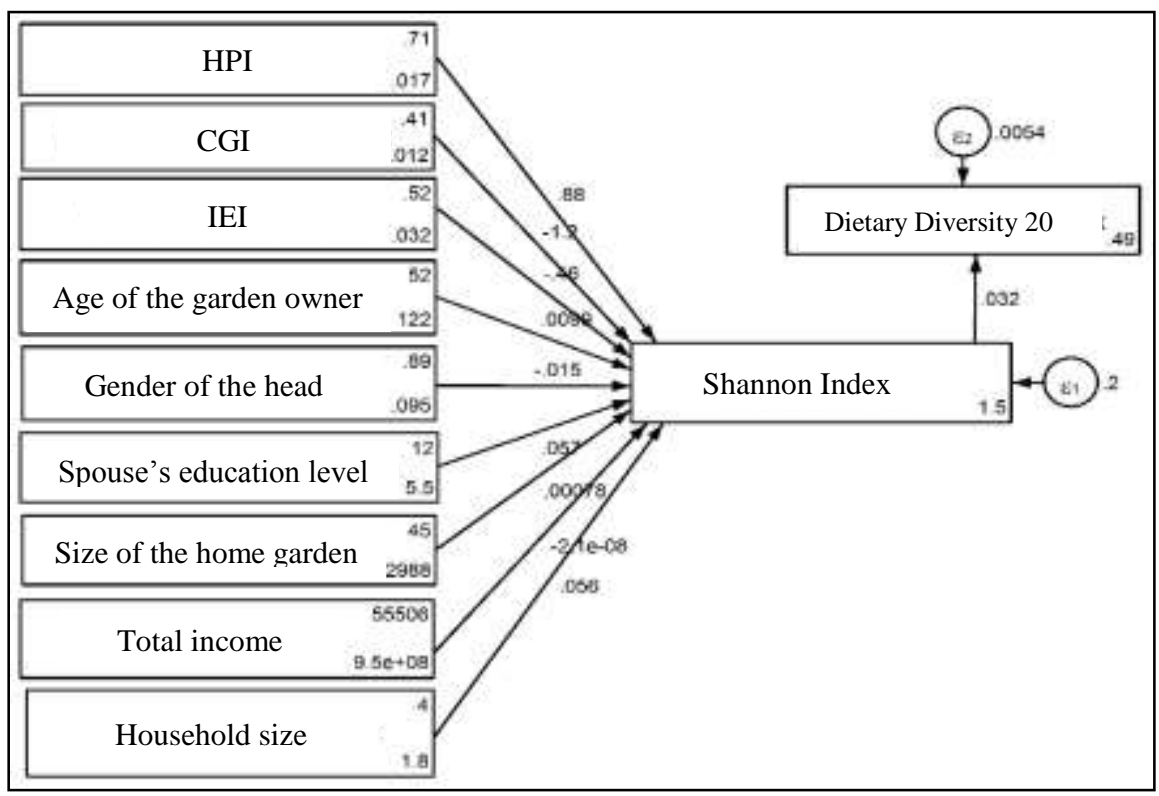

Figure 4: Path diagram of the SEM ${ }^{1}$

\footnotetext{
${ }^{1}$ In SEM, the path diagram consists of boxes and circles, which are connected by arrows. Observed variables are represented by rectangles (or square boxes), and latent indicators by circles (or ellipses). The causal relationship in the model illustrates by single headed arrows or paths, while the variable at the tail causes the variable at the head of the arrow.
} 
Table 2: Outcome of the SEM

\begin{tabular}{cc}
\hline Variables & Coefficient \\
\hline Structural Shannon Index & \\
Age of the garden owner & $0.009 * *$ \\
Gender of household head & -0.015 \\
Education level of the spouse & $0.056^{* * *}$ \\
Household size & 0.056 \\
Total income & 0.000 \\
Size of the home garden & 0.001 \\
HPI & $0.885^{* *}$ \\
CGI & $-1.161^{* * *}$ \\
IEI & $-0.460^{*}$ \\
Constant & $1.488^{* * *}$ \\
Dietary Diversity 20 Index & \\
Shannon Index & $0.032^{* *}$ \\
Constant & $0.488^{* * *}$ \\
\hline
\end{tabular}

Note: *** Significant at 1\%, ** Significant at 5\%, * Significant at 10\%

Further, it is not surprising to see a significant positive relationship between the plant diversity and the education level of the spouse as well. Education increases the knowledge of people and their comprehension. On the other hand, in Sri Lanka, the role played by the house wife gives a substantial contribution to facilitate better food, and secure good nutritional status of her family, and hence, she always guides the family members in every household chores. From a sample which 89.4 percent accounts for male headed household heads, the education level of the house wife plays a critical role in making her home garden a highly diversified one, as her ultimate objective lies within maximizing dietary diversity of her household members through a home garden which is rich in plant diversity.

People who are concerned with their health and food, try to have a balanced diet. They prefer to consume fresh and chemical free food. Gardening may lead to realizing those aspects, while improving the conditions of the living environment. Not only the physical fitness, but also the mental fitness can be achieved when engaging in home gardening. According to The Wellness Beat (2013), a Netherlands study has proclaimed that gardening can fight stress even better than other relaxing leisure activities. Moreover, another study in Norway has suggested

Statistically, the single headed arrows or paths represent regression coefficients (Wright, 1921). 
that paying fullest efforts in gardening may deliver better mental health. Further, FAO (2010) declared that home gardens through an established tradition, are greatly capable of improving household food security and alleviating micronutrient deficiencies. In light of this, it is obvious to gain a positive significant coefficient to the HPI, because, as long as the owner of the home garden being aware of these benefits, it may drive towards positive attitudes and ultimately, a better plant diversity.

However, enthusiasm on any activity is definitely reduced if someone has to meet with constraints, and same applies to the gardening as well. As the problems of gardening increases, people may get fed-up with it. Even though the household income is not significant with the plant diversity in this study, its role in generating a higher capital is enormous. Mmom (2009) stated that the relationship between biodiversity and household income should be positive, while a similar association has been revealed in the Kandy district by Korale-Gedara et al. (2012). So that, in a nature where the capital and income share quite a strong link with each other, the limitations of these influences will surely demotivate the owner, and as a result, plant diversity of the home garden will be adversely affected. This may be the reason for the significance of CGI with a negative coefficient.

Being complying with the findings of Abdoellah et al. (2006), Bernholt et al. (2009) and Major et al. (2005), this study too implies a negative relationship between the degree of commercialization and plant diversity, by reporting a negative coefficient for the IEI. When the objective becomes the commercialization, people tend to grow more plants in the same species as it facilitates more convenient management, than that of managing multiple plants in different species. Thus, a reduction of plant diversity can be expected, when people take home gardening as an income source.

In addition to the above consequences, it is noteworthy to consider the significant positive nexus between the SI (plant diversity) and DD20 (dietary diversity) reflected by the outcome of the SEM. Being simultaneously significant with the determinants of the plant diversity, it implies that age of the owner, education level of the spouse, HPI, CGI and IEI will have a significant impact on the dietary diversity in the same manner as they influence the plant diversity. Hence, increasing plant diversity in home gardens may lead to a more dietary diversity in household consumption, which drives towards the achievement of food and nutritional security of households.

\section{Conclusions and Recommendations}

By employing SEM, this study reveals a positive nexus between the plant diversity and dietary diversity in home gardens in Kandy district, highlighting age of the garden owner, education level of the spouse, HPI, CGI and IEI as significant drivers. As a result of these consequences, home gardening can play a major role in delivering a healthy diet to the community. Therefore, sound management of the significant determinants is essential in order to ensure the household food and nutrition security. 
As lack of bio diversity is visible in the home gardens which are managed by young members, they should be encouraged and, knowledge should be properly disseminated through universities, research and other agricultural institutions. In addition, by introducing incentives and subsidy schemes, government should lend a hand to the people who show reluctance to engage in home gardening due to the financial constraints.

Furthermore, when people shift towards commercial cultivation, it may have a negative impact on the diversity and structure of the home garden. In this context, if people come up with the purpose of achieving economic advantages, it may drive households away from the concerns on yielding sustainable benefits of home gardening. Hence, such groups should be motivated not only to maintain high relative abundance, but also to conserve high species richness, and so that, all relevant parties that are responsible for bio diversity, agriculture and health should have a greater responsibility in this regard.

\section{References}

Abdoellah, O. S., H. Y. Hadikusumah, K. Takeuchi and S. Okubo (2006). "Commercialization of home gardens in an Indonesian village: Vegetation composition and functional changes". Agroforestry systems, 68: 1-13.

Bernholt, H., K. Kehlenbeck, J. Gebauer and A. Buerkert (2009). "Plant species richness and diversity in urban and peri-urban gardens of Niamey, Niger". Agroforestry Systems, 77: 59-179.

DCS. (2002). Agriculture Census. Department of Census and Statistics, Sri Lanka.

FAO. (2009). "How to feed the world in 2050". Available online: http://www.fao.org/fileadmin/templates/wsfs/docs/expert_paper/How_to_Feed_the_ World_in_2050.pdf.

FAO. (2009). "Sri Lanka forestry sector outlook study by Forest Department". Working Paper No. APFSOS II/WP/2009/29. FAO, Regional Office for the Asia and the Pacific, Bangkok, Thailand.

FAO. (2010). "Improving nutrition through home gardening". Available online: http://www.fao.org/ag/agn/nutrition/household_gardens_en.stm.

FAO. (2015). "State of food insecurity in the world".

Hox, J. J. and T. M. Bechger (2000). "An introduction to Structural Equation Modeling”. Family Science Review, 11: 354-373.

Jacob, V. J. and W. S. Alles (1987). "Kandyan gardens of Sri Lanka”. Agroforestry Systems, 5: 123-137. 
Jayawardena, R., S. Thennakoon, N. Byrne, M. Soares, P. Katulanda and A. Hills (2014). "Energy and nutrient intakes among Sri Lankan adults". International Archives of Medicine, 7(34). Available online: http://www.intarchmed.com/content/7/1/34.

Kennedy, G., T. Ballard and M. Dop (2010). "Guidelines for measuring household and individual dietary diversity". Nutrition and Consumer Protection Division. Food and Agriculture Organization of the United Nations.

Korale-Gedara, P., J. Weerahewa, G. Pushpakumara and S. S. Kodothuwakku (2012). "Commercial orientation and its effects on plant diversity in home gardens: An empirical investigation of rural households in Sri Lanka”. Sri Lankan Journal of Agricultural Economics, 14/15: 17-42.

Lei, P. -W. and Q. Wu (2007). "Introduction to Structural Equation Modeling: Issues and practical considerations". Educational Measurement: Issues and Practice, 26(3): 3343. doi: 10.1111/j.1745-3992.2007.00099.x.

Major, J., C. R. Clement and A. Ditommaso (2005). "Influence of market orientation on food plant diversity of farms located on Amazonian Dark Earth in the region of Manaus, Amazonas, Brazil”. Economic Botany, 59: 77-86.

Mmom, P. C. (2009). "Impact of poverty and changing cropping systems on agro-crop diversity in the upper Niger Delta, Nigeria". IAIA09 Conference Proceedings', Impact Assessment and Human Well-Being 29 $9^{\text {th }}$ Annual Conference of the International Association for Impact Assessment.

Pollack, S. L. (2001). "Consumer demand for fruit and vegetables: The U.S. example", in Regmi, A. (Ed.), Changing structure of global food consumption and trade, Economic Research Service, U.S. Department of Agriculture, Washington, D.C. WRS-01-1 pp. 49-54.

Rashid, D. A., L. Smith and T. Rahman (2006). "Determinants of dietary quality: evidence from Bangladesh". American Agricultural Economics Association Annual Meeting; 2006 July 23-26; Long Beach, CA. Available online: http://ageconsearch.umn.edu/bitstream/21326/1/sp06ra11.pdf.

Regmi, A. (2001). "Changing structure of global food consumption and trade". Market and Trade Economics Division. Economic Research Service, USDA, Agriculture and Trade Report. WRS-01-1. United States Department of Agriculture, Washington, DC.

Ruel, M. T. (2003). "Is dietary diversity an indicator of food security or dietary quality? A review of measurement and research needs". Discussion paper no. 140. Food Consumption and Nutrition Division, International Food Policy Research Institute, Washington D.C.

Ruel, M. T. (2006). "Operationalizing dietary diversity: A review of measurement issues and research priorities". The Journal of Nutrition, 133(11): 3911-3926. 
The Wellness Beat. (2013). "The health benefits of gardening you may not know". Nonotuck Resource Associates, Inc., 2(1). Available online: http://www.nonotuck.com/wp-content/uploads/2014/04/Wellness-Newsletter-5.pdf.

Theil, H. and R. Finke (1983). “The consumer's demand for diversity", European Economic Review, 23: S395-S400.

Wright, S. (1921). "Correlation and causation". Journal of Agricultural Research, 20: 557585. 